\title{
A review of the evidence concerning hepatic glutathione depletion and susceptibility to hepatotoxicity after paracetamol overdose
}

This article was published in the following Dove Press journal:

Open Access Emergency Medicine

22 December 201I

Number of times this article has been viewed

\section{Sarbjeet S Kalsi ${ }^{1,2}$ \\ Paul I Dargan ${ }^{2-4}$ \\ W Stephen Waring ${ }^{5}$ \\ David M Wood ${ }^{2-4}$}

'Emergency Department, Guy's and St Thomas' NHS Foundation Trust, London, UK; ${ }^{2}$ Clinical Toxicology, Guy's and St Thomas' NHS Foundation Trust, London, UK; ${ }^{3}$ King's Health Partners, London, UK; ${ }^{4}$ King's College London, London, UK; ${ }^{5}$ York Teaching Hospital NHS Foundation Trust, York, UK
Correspondence: David Wood Medical Toxicology Office, 2nd Floor, Bermondsey Wing, Guy's Hospital, Great Maze Pond, London, SEI 9RT, UK

$\mathrm{Tel}+44207 / 885848$

Fax $+44207 / 881289$

Email david.wood@gstt.nhs.uk
Abstract: Paracetamol (acetaminophen) poisoning is common throughout the world. The management of nonstaggered (acute) paracetamol overdose is based on the plasma paracetamol concentration plotted on a treatment nomogram. In the UK there are two treatment lines on this nomogram, with the lower treatment line used for individuals felt to be at 'high risk' of paracetamol-related hepatotoxicity either as a result of induction of cytochrome P450 isoenzymes or reduction of intrahepatic glutathione. In this article we review the risk factors that, in current guidelines, are felt to increase risk due to a reduction in intrahepatic glutathione concentrations. Based on our review of the published literature, we feel that cystic fibrosis, acute viral illness, malnutrition, and eating disorders such as anorexia nervosa are likely to be associated with reduction in intrahepatic glutathione concentrations, and that this risk is likely to be related to malnutrition secondary to the disease. Chronic hepatitis $\mathrm{C}$ infection is also associated with reduced glutathione concentrations, although this appears to be independent of any associated malnutrition. Ageing and acute fasting are not associated with an increased risk of paracetamol-related hepatotoxicity due to reductions in glutathione concentrations. Finally, the evidence for HIV infection is inconclusive, particularly as the majority of studies were conducted in the pre-anti-viral treatment (HAART) era; however it is likely that patients with symptomatic HIV/AIDS have reduced glutathione concentrations due to associated malnutrition. Although there have been few studies which have specifically investigated whether there is an association between reduced intrahepatic glutathione concentrations and increased risk of paracetamol-related hepatotoxicity, in our opinion, it is likely that the above conditions that are associated with reduced glutathione concentrations, will be associated with an increased risk of paracetamol-related hepatotoxicity.

Keywords: glutathione, GSH, paracetamol, acetaminophen, hepatotoxicity, NAPQI

\section{Introduction}

The first cases reporting the association between paracetamol (acetaminophen, $\mathrm{N}$-acetyl-p-aminophenol, 4-hydroxyacetanilide) overdose and acute liver injury and fatal hepatotoxicity were reported in the $1960 \mathrm{~s} .{ }^{1,2}$ Acute paracetamol overdose is now the most common cause of acute liver injury and acute liver failure in the UK, US, Canada, Australia, and Scandinavia. ${ }^{3-7}$

The need for antidotal treatment with $\mathrm{N}$-acetylcysteine (NAC) in the management of an acute paracetamol overdose taken at a single timepoint (nonstaggered overdose) is determined by plotting the measured plasma paracetamol concentration against the interval after ingestion on the paracetamol treatment nomogram. ${ }^{8-10}$ There are currently two treatment nomograms used in the UK, known as the '200-line' and '100-line', 
or standard and high-risk treatment lines, respectively. ${ }^{10-12}$ The '200-line', starting at $200 \mathrm{mg} / \mathrm{L}$ at 4 hours postingestion, is used to determine the need for NAC treatment in those deemed to have 'normal' susceptibility to paracetamolrelated hepatotoxicty. The ' 100 -line' is $50 \%$ lower, and is used to determine the need for treatment in those who are deemed to be at higher risk of paracetamol-related hepatotoxicity. There are a number of different factors that are reported to be associated with increased risk. ${ }^{8-10,12-15}$ These factors can be broadly divided into the two following categories: (1) increased metabolism of paracetamol to the toxic metabolite N-acetyl-p-benzoquinoneimine (NAPQI) due to induction of the relevant cytochrome $\mathrm{P} 450$ isoenzymes (CYP2E1 and CYP3A4); and (2) reduction in liver glutathione stores. In our recent review published in this journal, we reviewed the data supporting an association between drugrelated induction of the cytochrome P450 isoenzyme system and paracetamol-related hepatotoxicity. ${ }^{15}$ This paper reviews the literature to determine whether factors that are currently considered to increase risk of hepatotoxicity following paracetamol overdose due to depletion of intrahepatic glutathione stores are in fact associated with an increased risk.

\section{Intrahepatic glutathione depletion}

Glutathione ( $\gamma$-glutamyl-cysteinyl-glycine, GSH) is a ubiquitous intracellular mammalian reduced-thiol and tripeptide molecule which helps maintain a balanced intracellular redox state by preferentially binding electrophilic molecules. ${ }^{16}$ It is particularly concentrated in hepatocytes, with the prevailing concentration of glutathione dependent on its rate of formation (which is rate-limited by both the availability of cysteine and the enzymatic activity of glutamate cysteine ligase), redox cycling from its glutathione disulfide form, and depletion following contact with highly electrophilic molecules, such as the paracetamol metabolite NAPQI. ${ }^{16-19}$

Once formed within hepatocytes, NAPQI preferentially binds to the cysteine residue of glutathione in a reaction catalyzed by glutathione S-transferase, resulting in a GSHNAPQI conjugate. ${ }^{16,18,19}$ This GSH-NAPQI conjugate is then metabolized stepwise by $\gamma$-glutamyl transpeptidase, dipeptidase, and $\mathrm{N}$-acetylase, cleaving off the $\gamma$-glutamyl and glycine residues to ultimately form inert cysteine and mercapturate conjugates that are renally excreted. ${ }^{16}$ This process prevents paracetamol-related hepatotoxicity, but at the price of irreversible consumption of glutathione. Although restoration of glutathione by de novo formation is normally quite rapid, when the amount and rate of NAPQI production exceeds the regeneration rate of glutathione, excess NAPQI is free to conjugate hepatic macromolecules, initiating hepatotoxicity. Animal studies correlate the degree of glutathione depletion with paracetamol-related hepatotoxicity, suggesting that hepatotoxicity ensues once glutathione levels diminish by more than $70 \%$ of normal values. ${ }^{19,20}$ Conversely, animals with above-normal intrahepatic glutathione levels, such as obese Zucker rats with 2.5 times the glutathione levels of lean Zucker rats, are protected against paracetamol-related hepatotoxicity, even after phenobarbital pretreatment that would normally be expected to enhance paracetamol-related hepatotoxicity. ${ }^{21}$ There is therefore the potential that patients who have low baseline intrahepatic glutathione may be at greater risk of developing paracetamol-related hepatotoxicity as they may have a reduced capacity to detoxify NAPQI. Selected examples of disorders associated with diminished intrahepatic glutathione are presented, with consideration of the available evidence concerning the relationship between these disorders and the risk of paracetamol-related hepatotoxicity.

\section{Congenital glutathione depletion and rare myopathies}

Patients with altered glutathione homeostasis - such as those with autosomal recessive glutathione synthetase deficiency have congenitally low glutathione levels. ${ }^{22}$ This condition is extremely rare, with less than 100 cases reported worldwide and therefore we feel that this is not likely to be of significance in terms of risk of paracetamol-related hepatotoxicity. A number of rare myopathy disorders are characterized by depletion of intracellular glutathione within myocytes, and anecdotal reports suggest that some patients might have increased susceptibility to paracetamol hepatotoxicity, even within the therapeutic dose range. ${ }^{23,24}$ However, the number of cases is too small to allow firm conclusions to be established, and few data exist concerning the relationship between glutathione concentrations in myocytes and within the liver in these patients.

\section{Human Immunodeficiency Virus (HIV) infection}

$\mathrm{HIV}$-infection is associated with a systemic reduction of available glutathione to $30 \%$ of normal values, as measured in plasma, lung epithelial lining fluid, and peripheral blood mononuclear cells. ${ }^{25-31}$ The systemic glutathione deficiency occurs in both established Acquired Immunodeficiency Syndrome (AIDS) as well as asymptomatic HIV-seropositive individuals. ${ }^{28}$ Total glutathione concentrations of asymptomatic HIV-seropositive individuals are reported as 30\% lower 
in plasma and 60\% lower in lung epithelial lining fluid compared to healthy HIV-seronegative controls, although there is no correlation between plasma and lung epithelial lining fluid levels. ${ }^{28,32}$ The reduction of glutathione in HIV is likely to be a result of decreased systemic synthesis of glutathione rather than over-consumption, possibly due to the diversion of the glutathione precursor cysteine towards viral protein production. ${ }^{27,30}$ Glutathione depletion also correlates with HIV-related morbidity. ${ }^{33}$

There are no data available to determine the effect of Highly Active Anti-Retroviral Therapy (HAART) on glutathione concentrations in patients with HIV. However, based on the above studies showing that depletion of glutathione is likely to be related to HIV morbidity (typically associated with high viral load, low CD4 count, or the presence of an AIDS defining diagnosis) we would expect that HAART would prevent, or reverse, these reductions in glutathione. It is important to note that the studies previously discussed were conducted in the pre-HAART era and therefore those individuals described as "asymptomatic" in these studies would be likely to still have high viral loads and low CD4 counts compared to "asymptomatic" individuals now on HAART who would have low/undetectable viral loads and high/normal CD4 counts.

Finally, it is unclear if the systemic glutathione deficiency seen in significant HIV infection is associated with reduced intrahepatic glutathione concentrations, as intrahepatic glutathione levels in lone HIV-seropositive patients have not been reported. However, simultaneous HIV and hepatits C infection results in reduced intrahepatic glutathione compared to either hepatitis $\mathrm{C}$ infection alone or noninfected controls. ${ }^{34}$

The evidence for HIV altering glucuronidation and sulfation of paracetamol is controversial. In one study, there was no difference in glucuronidation or sulfation after a subtherapeutic $(500 \mathrm{mg})$ dose of paracetamol between controls, asymptomatic HIV-positive individuals, and those with AIDS. ${ }^{35}$ However, another study investigating administration of a supratherapeutic ( $1.5 \mathrm{~g})$ dose of paracetamol demonstrated that there was significantly lower glucuronidation of paracetamol in individuals with AIDS compared to healthy volunteers and symptom-free HIV-positive patients. ${ }^{36}$ Although there was an increase in NAPQI formation, it is likely that this reflected reduced glucuronidation in the AIDS patients rather than CYP450 induction. This latter study is more relevant to the overdose situation, since the first study used subtherapeutic doses of paracetamol and therefore may have been negative as the dose of paracetamol used would not have exceeded hepatic glucuronidation capacity.
Hepatotoxicity has been reported in an HIV-positive patient after a subtherapeutic dose of paracetamol (3.3 g over 36 hours; maximum therapeutic dose over a 36-hour period $6 \mathrm{~g}$ ). ${ }^{37}$ However, the patient had been unwell for 48 hours prior to use of paracetamol with fever, rash, and gastrointestinal symptoms, and it is possible that the abnormal liver function could be explained by the underlying medical disorder (such as a viral infection) irrespective of paracetamol ingestion. Hepatotoxicity has also been reported in a 45-year-old with HIV infection who developed hepatotoxicity after receiving therapeutic doses of paracetamol. ${ }^{38}$ However, this patient had an underlying febrile illness, hepatitis $\mathrm{B}$ and hepatitis $\mathrm{C}$ infection, chronic alcohol use, malnutrition, and acute starvation. Therefore, in view of the multiple confounding medical factors it is not possible to assign causality to paracetamol in this case.

In summary, the evidence for whether HIV infection is associated with reduced intrahepatic glutathione stores and therefore an increased risk in patients presenting with paracetamol overdose is inconclusive and most of the data are from the pre-HAART era. There is the potential that patients with HIV infection, particularly those with symptomatic disease/AIDS will be at increased risk for paracetamolrelated hepatotoxicity and in our opinion these patients should be treated as high risk using the lower line on the paracetamol treatment nomogram.

\section{Hepatitis C infection}

Chronic hepatitis $\mathrm{C}$ infection was shown to be associated with diminished glutathione levels in plasma, liver, and in peripheral blood mononuclear cells in 105 patients with chronic hepatitis $\mathrm{C}$ infection compared to 51 healthy controls. ${ }^{34}$ This depletion of hepatic and mononuclear cell glutathione concentrations was greater in the 55 patients with coexistent HIV infection compared to the 50 patients without HIV infection. There appeared to be no correlation between the activity of HIV infection, as determined by the $\mathrm{T}$ cell subset CD4 concentration, and the additional reduction in glutathione concentrations. In terms of the hepatitis $\mathrm{C}$ infection, the reduction in glutathione in plasma, liver, and peripheral blood mononuclear cells was correlated to both the replication activity of hepatitis $\mathrm{C}$ virus in peripheral blood mononuclear cells and the grade/severity of liver disease as determined by the alanine aminotransferase concentration and histological and fibrosis scores of chronic hepatitis $\mathrm{C}$ infection.

A study investigating intrahepatic glutathione concentration failed to demonstrate a difference between six 
patients with no pathological changes on light microscopy of a liver biopsy specimen (mean glutathione concentration $26.9 \pm 8.1 \mu \mathrm{mol} / \mathrm{g}$ of hepatic protein) compared to those with "viral hepatitis," which included hepatitis C (mean glutathione concentration $47.4 \pm 25.9 \mu \mathrm{mol} / \mathrm{g}$ of hepatic protein). ${ }^{39}$

As noted above under the HIV infection section, there was a case of a 45-year-old with HIV and hepatitis C infection who developed hepatotoxicity related to regular "therapeutic use" of paracetamol. ${ }^{38}$ However, as noted above there were other confounding factors which either contributed to or were the main cause of the hepatotoxicity (underlying febrile illness, chronic alcohol use, malnutrition, and "illnessinduced starvation").

There was also a case of an individual with underlying hemophilia B and associated hepatitis C, who developed acute hepatotoxicity following supratherapeutic ingestion (6 g per day) of paracetamol. ${ }^{40}$ This patient was reported to also regularly drink in excess of 20 units of ethanol per day. It is therefore not possible to determine in this case the significance of the hepatitis $\mathrm{C}$ infection due to the underlying significant ethanol excess.

In the US Nationwide Inpatient Sample between 1998 and 2005, the effect of coexistent hepatitis $\mathrm{C}$ infection in patients presenting with paracetamol overdose was investigated. ${ }^{41}$ The Nationwide Inpatient Sample is a 20\% sample of all US hospitals; there were 42,781 paracetamol overdose hospitalizations in the sample. The prevalence of hepatitis $\mathrm{C}$ infection increased from $0.5 \%$ to $1.5 \%$ between 1998 and 2005 . After adjusting for other confounders and those individuals with pre-existing cirrhosis, the risk of acute liver injury increased with coexistent hepatitis $\mathrm{C}$ infection (adjusted odds ratio [OR]: $1.80,95 \%$ confidence interval $[\mathrm{CI}]: 1.30-2.48)$. Additionally, hepatitis $\mathrm{C}$ infection compared to those without infection was associated with greater risk of progression to severe liver failure (adjusted OR: 3.55, 95\% CI: 1.88-6.70) and a higher crude mortality $(2.1 \%$ vs $0.9 \%, P=0.01)$.

A further reanalysis of this same dataset has been undertaken to investigate if the increased risks associated with hepatitis $\mathrm{C}$ infection were due to an increased risk of unintentional overdose in patients with underlying liver disease. ${ }^{42}$ This reanalysis showed that the risk of acute liver injury was higher in patients with hepatitis $\mathrm{C}$ infection compared to those without for both intentional (12.2\% vs $6.4 \%)$ and unintentional (29.6\% vs $18.4 \%$ ) paracetamol overdose. Additionally, in the multivariate analysis, hepatitis $\mathrm{C}$ infection remained a significant predictor of acute liver injury (OR: 1.42, 95\% CI: 1.12-1.79) and liver failure (OR: 1.60, 95\% CI: 1.22-2.10).
Although there appears to be evidence that there is a significant increased risk of paracetamol-related hepatotoxicity in those with chronic hepatitis $\mathrm{C}$ infection, we have not been able to find any published evidence that paracetamol overdose in those with acute hepatitis $\mathrm{C}$ infection is associated with the same increased risk. However, as discussed in more detail below, those individuals with an acute viral illness such as acute hepatitis $\mathrm{C}$ infection, are likely to have relative intrahepatic glutathione depletion, and therefore should also be considered to be at higher risk of paracetamol-related hepatotoxicity.

\section{Intercurrent viral illness}

Acute infection with several different viruses has been shown to be associated with glutathione depletion: this has been noted for influenza, rhinovirus, and parainfluenza, all common human pathogens. ${ }^{43-45}$ The glutathione depletion is thought to be due to both cell leakage and preferential incorporation of cysteine into viral protein instead of glutathione. ${ }^{46}$ There are multiple case reports of children with concurrent acute viral illnesses reportedly developing paracetamol-related hepatotoxicity in the setting of repeated supratherapeutic ingestions. ${ }^{47-55}$ In one large series of 47 ill children experiencing paracetamolrelated hepatotoxicity after repeated supratherapeutic doses, the doses used were $60-420 \mathrm{mg} / \mathrm{kg} /$ day; allowing for possible inaccurate dose recall by parents, some children appeared to experience hepatotoxicity at what is generally considered subtoxic doses. ${ }^{51}$ In conclusion, it is likely that acute viral illness-induced glutathione depletion does increase the risk of paracetamol-related hepatotoxicity. Therefore, patients with a current viral illness presenting with acute paracetamol overdose should be treated using the high-risk line on the paracetamol treatment nomogram.

\section{Cystic fibrosis}

Glutathione concentrations in patients with cystic fibrosis have been shown to be reduced in both lung epithelial lining fluid, as well as systemically. ${ }^{56,57}$ In one study comparing 21 individuals with significant airway inflammation related to cystic fibrosis with 25 healthy controls, glutathione in both lung epithelial lining fluid and systemically (as measured in plasma) was significantly reduced compared to 25 healthy controls. ${ }^{56}$ In another study of 18 patients with cystic fibrosis, systemic glutathione (as measured in both whole blood and neutrophils) was significantly lower $(P<0.05)$ than in healthy controls; this deficiency was improved by oral NAC therapy. ${ }^{57}$ This suggests that the changes in glutathione are not a consequence of the airway inflammation seen in those 
with cystic fibrosis, but is related to a generalized deficiency of glutathione. The potential cause of this is that due to the underlying nature of cystic fibrosis, these individuals are relatively malnourished. There have been no studies which have assessed intrahepatic glutathione concentrations in patients with cystic fibrosis but it is likely given that these patients have decreased plasma glutathione that liver glutathione concentrations will also be reduced.

A study compared the metabolism of paracetamol in five individuals with cystic fibrosis to five age-matched healthy controls. ${ }^{58}$ Individuals were dosed with $16 \mathrm{mg} / \mathrm{kg}$ (peak paracetamol concentrations were $\leq 30 \mathrm{mg} / \mathrm{L}$ and therefore these individuals were given a supratherapeutic but subtoxic dose). Overall, the total plasma clearance of paracetamol was greater in those with cystic fibrosis $(0.362 \pm 0.081 \mathrm{~L} / \mathrm{hour} / \mathrm{kg})$ compared to controls $(0.247 \pm 0.022 \mathrm{~L} / \mathrm{hour} / \mathrm{kg})$. The increased clearance was due to increased glucuronidation (increased 1.7-fold) and sulfation (increased 1.8-fold) of paracetamol in the cystic fibrosis group compared to the healthy controls. This would suggest that patients with cystic fibrosis may potentially be at less risk of paracetamol-related hepatotoxicity, since there will be less paracetamol that can be metabolized through the cytochrome P450 isoenzyme system to NAPQI. However, these individuals were not given a potentially "toxic" concentration of paracetamol, and therefore it is possible that this increased glucuronidation and sulfation may be exceeded in a paracetamol overdose. Furthermore, the cystic fibrosis group had a lower body weight $(50.7 \pm 13.8 \mathrm{~kg})$ than the healthy controls $(69.9 \pm 9.8 \mathrm{~kg})-$ because drug clearance is typically normalized for body weight; it has been suggested that the reported difference in this study may in fact be an artefact of this adjustment. ${ }^{59}$

There is one case report of a 3-year-old child with cystic fibrosis who died following the use of a paracetamolcontaining product. ${ }^{60}$ However, the death was not clearly attributable to paracetamol. The product used was an acetylsalicylic acid ester of paracetamol, which is broken down into paracetamol and salicylic acid after ingestion. Dosing of this product is based on measurement of salicylate concentrations alone, which likely led to inadvertent supratherapeutic dosing of paracetamol. In addition to cystic fibrosis, the child had juvenile chronic polyarthritis. The child's underlying condition initially improved over the first 2 weeks of treatment, before the child became increasingly unwell with a high salicylate concentration of $390 \mathrm{mg} / \mathrm{L}$. Despite a dose reduction, the child continued to deteriorate and only at that time was the paracetamol concentration measured. This was $110 \mathrm{mg} / \mathrm{L}$ and there was increasing evidence of hepatic dysfunction.
The clinical condition continued to deteriorate and the child died; postmortem findings showed centrilobular hepatic necrosis and moderate cholestasis, which were attributed to paracetamol poisoning. Whilst the centrilobular necrosis would be consistent with acute paracetamol hepatotoxicity, we feel that it is likely that the cholestasis is attributable to salicylate-related Reye's Syndrome.

In conclusion, the evidence that cystic fibrosis is associated with an increased risk of hepatotoxicity due to reductions in glutathione concentrations in our opinion is inconclusive. We feel it is likely that any potential increased risk is not due to the underlying cystic fibrosis, but instead to the reduction in body weight and/or relative malnutrition seen in individuals with cystic fibrosis due to associated recurrent infections and respiratory disease seen in cystic fibrosis. Therefore, based on the current available literature, patients with cystic fibrosis should only be treated as high risk for paracetamol poisoning if they are malnourished.

\section{Malnutrition, starvation, and fasting}

Studies in rats suggest that protein calorie malnutrition reduces both glutathione concentrations and cytochrome P450 activity, and that these effects are reversed by cysteine supplementation. ${ }^{61-64}$ Despite the reduced cytochrome P450 activity, the dose of paracetamol required to kill half the study animals $\left(\mathrm{LD}_{50}\right)$ is halved in starved rats. This suggests that starvation-induced glutathione depletion outweighs any reduction in cytochrome P450 activity, leading to an increased risk of paracetamol-related hepatotoxicity ${ }^{63}$

Additionally, in rats, starvation causes increased glucuronidation at the expense of sulfation; ${ }^{65}$ this study did not however report on the production of NAPQI. Mehta et al studied the pharmacokinetic profile following a $10 \mathrm{mg} / \mathrm{kg}$ paracetamol dose in eleven children with protein calorie malnutrition (five with kwashiorkor) and compared them to five healthy children. ${ }^{66}$ Those children with protein calorie malnutrition had a reduction in the paracetamol elimination rate constant $\left(\mathrm{K}_{\mathrm{e}} 0.108 \pm 0.015\right.$ per hour in those with malnutrition compared to $0.170 \pm 0.022$ per hour in controls) and an increased paracetamol half-life $(8.14 \pm 1.30$ hours in those with malnutrition compared to $4.33 \pm 0.52$ hours in controls). The study was repeated in five patients after correction of their protein calorie malnutrition, and the effects of malnutrition were no longer present. It is important to note that in this study they did not look to determine whether there was altered metabolism of paracetamol to determine whether these changes would be of clinical significance in determining the risk of paracetamol-related hepatotoxicity. It should be 
noted that with the change in half-life of paracetamol, the interpretation of the paracetamol concentration against the paracetamol treatment nomogram may not be appropriate, as this is based on a typical 4-hour half-life. However, there are no further studies to suggest that we should change the treatment line slope for those with protein calorie malnutrition, and therefore we would recommend treating those with protein calorie malnutrition on the same treatment nomogram but using the high-risk treatment line.

In contrast, acute fasting does not appear to alter paracetamol metabolism. Lee et al administered a therapeutic dose of paracetamol to four obese patients who had a mean $13 \mathrm{~kg}$ weight loss from dieting before dosage, and reported that paracetamol pharmacokinetics was unchanged; it should be noted, however, that they did not examine the production of NAPQI or related metabolites.$^{67} \mathrm{~A}$ subsequent well-designed study examined the effect of 500 calorie restriction in six obese (body weight $>30 \%$ of normal) otherwise healthy volunteers given $2000 \mathrm{mg}$ paracetamol before and after 5 days of this strict diet. ${ }^{68}$ The authors found that, despite modest mean weight loss of $2.7 \mathrm{~kg}$, there was no alteration in the percentages of the various paracetamol metabolites (including mercapturic conjugates) retrieved from urine. ${ }^{68}$

There are two relevant clinical studies examining the correlation between reduced food intake and paracetamolrelated hepatotoxicity. Whitcomb and Block retrospectively identified 49 patients over a 6 -year period from a single institution with paracetamol overdose ( $>4 \mathrm{~g} / 24$ hours ingestion) and evidence of hepatotoxicity (AST $>1000 \mathrm{IU} / \mathrm{L}) .{ }^{69}$ More detailed analysis of data from these patients was only undertaken for those presenting with unintentional paracetamol hepatotoxicity, ie, staggered supratherapeutic ingestions. In this group of patients, and in those who had ingested $<10 \mathrm{~g} / 24$ hours, fasting was associated with hepatotoxicity. ${ }^{68}$ In those who had ingested $>10 \mathrm{~g} / 24$ hours, chronic excessive ethanol intake was more associated with hepatotoxicity than fasting. It should be noted that a significant proportion of patients self-reported underlying viral type symptoms which, as discussed earlier, could have increased the risk of paracetamol-related hepatotoxicity. Additionally, the effect of fasting was only studied in those with paracetamol-related hepatotoxicity. There was no assessment of the proportion of patients who self-reported fasting but did not develop hepatotoxicity and the effect was only studied in staggered non-single time point ingestions. In a prospective study of 1085 patients with paracetamol overdose, serum urea, which was used as a marker of reduced protein catabolism secondary to malnutrition and cachexia, did not predict paracetamol-related hepatotoxicity. ${ }^{70}$

In conclusion, existing data suggest that malnutrition, and in particular protein calorie malnutrition, is associated with altered paracetamol metabolism and an increased risk of paracetamol-related hepatotoxicity. There is difficulty in ascertaining the contribution of acute starvation to susceptibility to liver toxicity because fewer data exist concerning this patient group. Potential concerns have resulted in recent advice offered by the National Poisons Information Service in the UK to consider such patients as high risk in determining the need for NAC. Further work is required to explore the extent and duration of starvation that might be clinically relevant in terms of hepatotoxicity risk.

\section{Eating disorders}

In a controlled study comparing eleven patients with anorexia nervosa to twelve matched healthy controls, a low body mass index was associated with reduced systemic glutathione and cysteine ${ }^{71}$ There was no reduction in the precursor amino acids of glutathione, and therefore the authors concluded that the decreased glutathione was due to reduced synthesis. It is unclear what effect anorexia has on hepatic conjugation and cytochrome P450 oxidation of paracetamol, but it is likely the pattern would be similar to the effect of protein calorie malnutrition. The clinical effect of altered glutathione levels in anorexia is uncertain: one case report of an anorexic patient who had ingested $15 \mathrm{~g}$ paracetamol reported an uneventful clinical course following appropriate treatment with NAC. ${ }^{72}$

There are no relevant cohort studies reporting on the outcomes of patients with both anorexia nervosa and paracetamol poisoning. However, in our opinion, individuals with a diagnosis of anorexia nervosa who have clinical evidence of malnutrition should be considered to be at higher risk of paracetamol-related hepatotoxicity, for the reasons discussed in the section above. There is no clear evidence as to when a person who has had a previous diagnosis of anorexia nervosa and has had treatment should no longer be considered to be at higher risk of hepatotoxicity. Without any clear evidence in this area, we would recommend an individual who clinically appears no longer to have anorexia (eg, normal/near-normal body mass index and/or self-reported history of eating normally or relatively normally) should be considered to be at normal risk and no longer at higher risk of paracetamolrelated hepatotoxicity.

Irrespective of hepatotoxicity risk, it is recognized that paracetamol overdose is associated with the occurrence of 
hypokalemia in a dose-dependent manner. ${ }^{73}$ This may be of importance in the setting of drug overdose given that psychiatric disease might be an independent contributor to hypokalemia. ${ }^{74}$

Although bulimia nervosa is reported to be associated with a higher risk of paracetamol-related hepatotoxicity, we have been unable to find any published data on this association of increased risk. Unlike anorexia nervosa, a significant proportion of individuals with bulimia nervosa may not be underweight or have evidence of malnutrition. However, in our opinion, given that bulimia nervosa can be associated with malnutrition, we feel that those individuals with this underlying diagnosis who have clinical evidence of malnutrition should be treated according to the high-risk treatment line.

\section{Aging}

Aging is known to affect the hepatic metabolism of many drugs. Reduced clearance of drugs has been related to a $30 \%-40 \%$ reduction in liver volume, liver blood flow, and liver perfusion between the third and tenth decades of life. ${ }^{75}$ Although standard reference values for liver function tests are not altered by aging, dynamic liver function tests are reduced selectively. ${ }^{76}$ For instance, hepatic nitrogen clearance is significantly impaired by $30 \%$ amongst volunteers aged $>70$ years compared to $<55$ years. ${ }^{77}$ Also, the hepatic content of cytochrome $\mathrm{P} 450$ peaks by the age of 40 , before declining by $16 \%$ up to 69 years of age, and by $32 \%$ beyond 70 years of age. ${ }^{78}$ The clearance of drugs metabolized by the cytochrome P450 system is thus reduced by up to $50 \%$ in elderly patients. ${ }^{79}$

These alterations are relevant to paracetamol metabolism. Pharmacokinetic studies utilizing therapeutic paracetamol doses show that paracetamol clearance is reduced. ${ }^{80-82}$ This is associated with an altered proportional paracetamol clearance: when elderly patients (mean age 70.3 years) were compared to younger patients (mean age 23.1 years), the older patients had similar formation of glucuronide and glutathione conjugates, but significantly less sulfation (by $23.1 \%$ ) and direct excretion of unchanged paracetamol (by $42.9 \%$ ). ${ }^{82}$ The glucuronidation capacity is, however, impaired in frail elderly patients. ${ }^{83}$ There have been no toxicokinetic studies in elderly patients with paracetamol overdose; however, it is conceivable that the effects of diminished paracetamol clearance (thus increasing the paracetamol burden) may be offset by reduced cytochrome P450 function forming less NAPQI. However, it is likely that glutathione is less able to detoxify the NAPQI that is formed, as the functional capacity of the GSH/glutathione disulfide antioxidant system has been reported to decline in those aged over 45 years. $^{84}$

There are a number of studies which have shown that increasing age is associated with an increased risk of paracetamol-related hepatotoxicity. ${ }^{41,85,86}$ In the US Nationwide Inpatient Sample described above, an increase in age of 10 years was associated with an increased risk of acute liver injury (OR: 1.21, 95\% CI: 1.18-1.25), severe liver injury (OR: 1.46, 95\% CI: 1.34-1.58), and in-hospital mortality (OR: 1.6, 95\% CI: 1.49-1.71). ${ }^{41}$ Subsequent reanalysis of this dataset showed that when increasing age per year was analyzed, this was not significantly associated with acute liver injury (OR: 1.01, 95\% CI: $1.0-1.01) .{ }^{42}$ However, it is possible that this latter reanalysis did not show any differences due to the fact that any potential changes in liver function and activity are not of clinical significance when considered on a year-by-year basis, but are of clinical significance when longer age-range comparisons are undertaken, as in the initial data analysis.

In a study of 75 patients with paracetamol overdose in Taiwan, multiple logistic regression analysis of risk factors for hepatotoxicity showed that age was an independent risk factor and patients with "major hepatotoxicity" were older (32.5 vs 24.2 years, $P=0.019$ ) than those with no/minor hepatotoxicity. ${ }^{85}$ In a larger study of patients presenting with acute liver failure (ALF) from all causes, 1016 were aged under 60 years, $49.1 \%$ had paracetamol-induced ALF and in the 110 patients aged over 60 years, $22.7 \%$ had paracetamolinduced ALF. ${ }^{86}$ Multiple logistic regression analysis showed that age was not an independent risk factor for spontaneous survival. Subsequent analysis of those aged over 40 compared to those aged under 40 demonstrated that spontaneous survival was greater in the younger group $(68.0 \%$ vs $58.9 \%$, $P=0.043$ ), although overall survival and transplantation rates did not differ between the two groups. ${ }^{86}$

Whilst some studies suggest that increasing age is a risk factor for paracetamol-related hepatotoxicity, other studies suggest that this may not be the case. Some of the risks seen may represent other factors in addition to age such as underlying comorbidities and malnutrition in the elderly. In addition there is the potential that physicians may have been less likely to refer elderly patients to a liver transplant center and/or that elderly patients may be less likely to be listed for transplantation. Overall, we feel that the clinical importance of age as a risk factor is likely to be minimal and elderly patients should be treated as all other patients in terms of risk stratification for paracetamol overdose. 


\section{Conclusions}

Intrahepatic glutathione detoxifies the toxic metabolite of paracetamol, NAPQI, that is responsible for paracetamolrelated hepatotoxicity. ${ }^{18,19}$ Animal studies suggest that the rate of glutathione depletion correlates with paracetamol-related hepatotoxicity, and that hepatotoxicity occurs with loss of over $70 \%$ of intrahepatic glutathione stores from normal values. ${ }^{19,20}$ Therefore, individuals who have low baseline intrahepatic glutathione are likely to be at greater risk of developing paracetamol-related hepatotoxicity.

Current guidelines in the UK for the management of acute paracetamol overdose include a number of conditions reported to be associated with diminished intrahepatic glutathione concentrations as factors associated with increased risk of paracetamol-related hepatotoxicity. Based on our review of the published literature, HIV infection, chronic hepatitis $\mathrm{C}$ infection, cystic fibrosis, malnutrition, and eating disorders such as anorexia nervosa are likely to be associated with reduction in intrahepatic glutathione concentrations. However, the published literature does not always appear to correlate the association between reduced intrahepatic glutathione concentrations and increased risk of paracetamolrelated hepatotoxicity. The evidence for HIV infection is inconclusive and the majority of studies were conducted in the pre-HAART era and may not reflect current management and clinical outcomes in HIV infection. Additionally, the association with cystic fibrosis and eating disorders such as anorexia nervosa appear not to be related to the underlying medical conditions per se, but instead to the association with malnutrition. Part of the difficulty in determining risk in a clinical setting is the lack of a readily accessible measure of hepatic glutathione stores. A number of simple blood and urinary markers have been explored, but these have either proven to be ineffective or there are insufficient data to support their use as a surrogate marker, for example serum glutathione transferase activity, enzyme-uria, and proteinuria. ${ }^{87-89}$

Therefore, in our opinion, the risk of paracetamol-related hepatotoxicity related to reduction in intrahepatic glutathione concentrations is related to malnutrition, and in particular protein calorie malnutrition, whether this is a primary diagnosis or secondary to another underlying medical condition. Finally, based on the published medical literature, chronic hepatitis $\mathrm{C}$ infection, independent of any associated malnutrition, is associated with increased risk of paracetamol-related hepatotoxicity.

\section{Disclosure}

The authors report no conflicts of interest in this work.

\section{References}

1. Davidson DG, Eastham WN. Acute liver necrosis following overdose of paracetamol. Br Med J. 1966;2:497-499.

2. Thomson JS, Prescott LF. Liver damage and impaired glucose tolerance after paracetamol overdosage. $\mathrm{Br}$ Med J. 1966;2:506-507.

3. Gow PJ, Smallwood RA, Angus PW. Paracetamol overdose in a liver transplantation centre: an 8-year experience. J Gastroenterol Hepatol. 1999; 14:817-821.

4. Brandsaeter B, Hockerstedt K, Friman S, et al. Fulminant hepatic failure: outcome after listing for highly urgent liver transplantation - 12 years experience in the nordic countries. Liver Transpl. 2002;8:1055-1062.

5. Tessier G, Villeneuve E, Villeneuve JP. Etiology and outcome of acute liver failure: experience from a liver transplantation centre in Montreal. Can J Gastroenterol. 2002;16:672-676.

6. Larson AM, Polson J, Fontana RJ, et al. Acetaminophen-induced acute liver failure: results of a United States multicenter, prospective study. Hepatology. 2005;42:1364-1372.

7. Bernal W, Cross TJ, Auzinger G, et al. Outcome after wait-listing for emergency liver transplantation in acute liver failure: a single centre experience. J Hepatol. 2009;50:306-313.

8. Wolf SJ, Heard K, Sloan EP, Jagoda AS. Clinical policy: critical issues in the management of patients presenting to the emergency department with acetaminophen overdose. Ann Emerg Med. 2007;50:292-313.

9. Daly FF, Fountain JS, Murray L, Graudins A, Buckley NA. Guidelines for the management of paracetamol poisoning in Australia and New Zealand - explanation and elaboration. A consensus statement from clinical toxicologists consulting to the Australasian poisons information centres. Med J Aust. 2008;188:296-301.

10. NPIS. TOXBASE: The primary clinical toxicological database of the National Poisons Information Service. National Poisons Information Service. Available from: http://www.toxbase.org/Poisons-Index-AZ/P-Products/Paracetamol------------. Accessed April 8, 2011.

11. Vale JA, Proudfoot AT. Paracetamol (acetaminophen) poisoning. Lancet. 1995;346:547-552.

12. Wallace CI, Dargan PI, Jones AL. Paracetamol overdose: an evidence based flowchart to guide management. Emerg Med J. 2002;19: 202-205.

13. Clemmesen JO, Ott P, Dalhoff KP, Astrup LB, Tage-Jensen U, Poulsen HE. Recommendations for treatment of paracetamol poisoning. Ugeskr Laeger. 1996;158:6892-6895. Danish.

14. Brok J, Buckley N, Gluud C. Interventions for paracetamol (acetaminophen) overdose. Cochrane Database Syst Rev. 2006;2: CD003328.

15. Kalsi SS, Wood DM, Waring WS, Dargan PI. Does cytochrome p450 liver isoenzyme induction increase the risk of liver toxicity after paracetamol overdose? Open Access Emerg Med. 2011;3:1-8.

16. Lu SC. Regulation of glutathione synthesis. Mol Aspects Med. 2009; 30:42-59.

17. Griffith OW. Biologic and pharmacologic regulation of mammalian glutathione synthesis. Free Radic Biol Med. 1999;27:922-935.

18. Mitchell JR, Jollow DJ, Potter WZ, Davis DC, Gillette JR, Brodie BB. Acetaminophen-induced hepatic necrosis. I. Role of drug metabolism. J Pharmacol Exp Ther. 1973;187:185-194.

19. Mitchell JR, Jollow DJ, Potter WZ, Gillette JR, Brodie BB. Acetaminophen-induced hepatic necrosis. IV. Protective role of glutathione. J Pharmacol Exp Ther. 1973;187:211-217.

20. Davis DC, Potter WZ, Jollow DJ, Mitchell JR. Species differences in hepatic glutathione depletion, covalent binding and hepatic necrosis after acetaminophen. Life Sci. 1974;14:2099-2109.

21. Blouin RA, Dickson P, McNamara PJ, Cibull M, McClain C. Phenobarbital induction and acetaminophen hepatotoxicity: resistance in the obese Zucker rodent. J Pharmacol Exp Ther. 1987;243:565-570.

22. Ristoff E, Larsson A. Patients with genetic defects in the gammaglutamyl cycle. Chem Biol Interact. 1998;111-112:113-121.

23. Ceelie I, James LP, Gijsen V, et al. Acute liver failure after recommended doses of acetaminophen in patients with myopathies. Crit Care Med. 2011;39:678-682. 
24. Gunst JJ, Langlois MR, Delanghe JR, De Buyzere ML, Leroux-Roels GG. Serum creatine kinase activity is not a reliable marker for muscle damage in conditions associated with low extracellular glutathione concentration. Clin Chem. 1998;44:939-943.

25. Roederer M, Staal FJ, Osada H, Herzenberg LA. CD4 and CD8 T cells with high intracellular glutathione levels are selectively lost as the HIV infection progresses. Int Immunol. 1991;3:933-937.

26. Staal FJ, Roederer M, Israelski DM, et al. Intracellular glutathione levels in T cell subsets decrease in HIV-infected individuals. AIDS Res Hum Retroviruses. 1992;8:305-311.

27. De Quay B, Malinverni R, Lauterburg BH. Glutathione depletion in HIV-infected patients: role of cysteine deficiency and effect of oral $\mathrm{N}$-acetylcysteine. AIDS. 1992;6:815-819.

28. Buhl R, Jaffe HA, Holroyd KJ, et al. Systemic glutathione deficiency in symptom-free HIV-seropositive individuals. Lancet. 1989;2: 1294-1298.

29. Eck HP, Gmunder H, Hartmann M, Petzoldt D, Daniel V, Droge W. Low concentrations of acid-soluble thiol (cysteine) in the blood plasma of HIV-1-infected patients. Biol Chem Hoppe Seyler. 1989;370: 101-108.

30. Helbling B, von Overbeck J, Lauterburg BH. Decreased release of glutathione into the systemic circulation of patients with HIV infection. Eur J Clin Invest. 1996;26:38-44.

31. Gil L, Martinez G, Gonzalez I, et al. Contribution to characterization of oxidative stress in HIV/AIDS patients. Pharmacol Res. 2003; $47: 217-224$

32. Holroyd KJ, Buhl R, Borok Z, et al. Correction of glutathione deficiency in the lower respiratory tract of HIV seropositive individuals by glutathione aerosol treatment. Thorax. 1993;48:985-989.

33. Herzenberg LA, De Rosa SC, Dubs JG, et al. Glutathione deficiency is associated with impaired survival in HIV disease. Proc Natl Acad Sci US A. 1997;94:1967-1972.

34. Barbaro G, Di Lorenzo G, Soldini M, et al. Hepatic glutathione deficiency in chronic hepatitis $\mathrm{C}$ : quantitative evaluation in patients who are HIV positive and HIV negative and correlations with plasmatic and lymphocytic concentrations and with the activity of the liver disease. Am J Gastroenterol. 1996;91:2569-2573.

35. O’Neil WM, Pezzullo JC, Di Girolamo A, Tsoukas CM, Wainer IW. Glucuronidation and sulphation of paracetamol in HIV-positive patients and patients with AIDS. Br J Clin Pharmacol. 1999;48:811-818.

36. Esteban A, Perez-Mateo M, Boix V, Gonzalez M, Portilla J, Mora A. Abnormalities in the metabolism of acetaminophen in patients infected with the human immunodeficiency virus (HIV). Methods Find Exp Clin Pharmacol. 1997;19:129-132.

37. Shriner K, Goetz MB. Severe hepatotoxicity in a patient receiving both acetaminophen and zidovudine. Am J Med. 1992;93:94-96.

38. Moling O, Cairon E, Rimenti G, Rizza F, Pristera R, Mian P. Severe hepatotoxicity after therapeutic doses of acetaminophen. Clin Ther 2006;28:755-760.

39. Poulsen HE, Ranek L, Andreasen PB. The hepatic glutathione content in liver diseases. Scand J Clin Lab Invest. 1981;41:573-576.

40. Leach M, Makris M, Gleeson DC, Preston FE. Acute liver failure induced by alcohol and paracetamol in an HCV-infected haemophiliac. Br J Haematol. 1998;103:891-893.

41. Nguyen GC, Sam J, Thuluvath PJ. Hepatitis C is a predictor of acute liver injury among hospitalizations for acetaminophen overdose in the United States: a nationwide analysis. Hepatology. 2008;48:1336-1341.

42. Myers RP, Shaheen AA. Hepatitis C, alcohol abuse, and unintentional overdoses are risk factors for acetaminophen-related hepatotoxicity. Hepatology. 2009;49:1399-1400.

43. Nencioni L, Iuvara A, Aquilano K, et al. Influenza A virus replication is dependent on an antioxidant pathway that involves GSH and Bcl-2. FASEB J. 2003;17:758-760.

44. Papi A, Papadopoulos NG, Stanciu LA, et al. Reducing agents inhibit rhinovirus-induced up-regulation of the rhinovirus receptor intercellular adhesion molecule-1 (ICAM-1) in respiratory epithelial cells. FASEB J. 2002;16:1934-1936.
45. Garaci E, Palamara AT, Di Francesco P, Favalli C, Ciriolo MR, Rotilio G. Glutathione inhibits replication and expression of viral proteins in cultured cells infected with Sendai virus. Biochem Biophys Res Commun. 1992;188:1090-1096.

46. Ciriolo MR, Palamara AT, Incerpi S, et al. Loss of GSH, oxidative stress, and decrease of intracellular $\mathrm{pH}$ as sequential steps in viral infection. J Biol Chem. 1997;272:2700-2708.

47. Calvert LJ, Linder CW. Acetaminophen poisoning. J Fam Pract. 1978;7:953-956.

48. Clark JH, Russell GJ, Fitzgerald JF. Fatal acetaminophen toxicity in a 2-year-old. J Indiana State Med Assoc. 1983;76:832-835.

49. Douidar SM, al-Khalil I, Habersang RW. Severe hepatotoxicity, acute renal failure, and pancytopenia in a young child after repeated acetaminophen overdosing. Clin Pediatr (Phila). 1994;33:42-45.

50. Henretig FM, Selbst SM, Forrest C, et al. Repeated acetaminophen overdosing. Causing hepatotoxicity in children. Clinical reports and literature review. Clin Pediatr (Phila). 1989;28:525-528.

51. Heubi JE, Barbacci MB, Zimmerman HJ. Therapeutic misadventures with acetaminophen: hepatoxicity after multiple doses in children. J Pediatr. 1998;132:22-27.

52. Nogen AG, Bremner JE. Fatal acetaminophen overdosage in a young child. J Pediatr. 1978;92:832-833.

53. Smith DW, Isakson G, Frankel LR, Kerner Jr JA. Hepatic failure following ingestion of multiple doses of acetaminophen in a young child. J Pediatr Gastroenterol Nutr. 1986;5:822-825.

54. Muniz AE, Rose SR 2nd, Liner SR, Foster RL. Unsuspected acetaminophen toxicity in a 58-day-old infant. Pediatr Emerg Care. 2004; 20:824-828

55. Swetnam SM, Florman AL. Probable acetaminophen toxicity in an 18-month-old infant due to repeated overdosing. Clin Pediatr (Phila). 1984;23:104-105.

56. Roum JH, Buhl R, McElvaney NG, Borok Z, Crystal RG. Systemic deficiency of glutathione in cystic fibrosis. J Appl Physiol. 1993; 75:2419-2424.

57. Tirouvanziam R, Conrad CK, Bottiglieri T, Herzenberg LA, Moss RB. High-dose oral $\mathrm{N}$-acetylcysteine, a glutathione prodrug, modulates inflammation in cystic fibrosis. Proc Natl Acad Sci U S A. 2006; 103:4628-4633.

58. Hutabarat RM, Unadkat JD, Kushmerick P, Aitken ML, Slattery JT, Smith AL. Disposition of drugs in cystic fibrosis. III. Acetaminophen. Clin Pharmacol Ther. 1991;50:695-701.

59. Weinberger MM. Drug clearance in patients with cystic fibrosis. Clin Pharmacol Ther. 1992;52:106-107.

60. Symon DN, Gray ES, Hanmer OJ, Russell G. Fatal paracetamol poisoning from benorylate therapy in child with cystic fibrosis. Lancet. 1982;2:1153-1154.

61. Cho MK, Kim YG, Lee MG, Kim SG. Suppression of rat hepatic cytochrome $\mathrm{P} 450 \mathrm{~s}$ by protein-calorie malnutrition: complete or partial restoration by cysteine or methionine supplementation. Arch Biochem Biophys. 1999;372:150-158.

62. Kim YG, Kim SK, Kwon JW, et al. Effects of cysteine on amino acid concentrations and transsulfuration enzyme activities in rat liver with protein-calorie malnutrition. Life Sci. 2003;72:1171-1181.

63. McLean AE, Day PA. The effect of diet on the toxicity of paracetamol and the safety of paracetamol-methionine mixtures. Biochem Pharmacol. 1975;24:37-42.

64. Wendel A, Feuerstein S, Konz KH. Acute paracetamol intoxication of starved mice leads to lipid peroxidation in vivo. Biochem Pharmacol. 1979;28:2051-2055.

65. Jung D. Disposition of acetaminophen in protein-calorie malnutrition. J Pharmacol Exp Ther. 1985;232:178-182.

66. Mehta S, Nain CK, Yadav D, Sharma B, Mathur VS. Disposition of acetaminophen in children with protein calorie malnutrition. Int J Clin Pharmacol Ther Toxicol. 1985;23:311-315.

67. Lee WH, Kramer WG, Granville GE. The effect of obesity on acetaminophen pharmacokinetics in man. J Clin Pharmacol. 1981;21: $284-287$. 
68. Schenker S, Speeg KV Jr, Perez A, Finch J. The effects of food restriction in man on hepatic metabolism of acetaminophen. Clin Nutr. 2001;20:145-150.

69. Whitcomb DC, Block GD. Association of acetaminophen hepatotoxicity with fasting and ethanol use. JAMA. 1994;272:1845-1850.

70. Waring WS, Stephen AF, Robinson OD, Dow MA, Pettie JM. Serum urea concentration and the risk of hepatotoxicity after paracetamol overdose. QJM. 2008;101:359-363.

71. Zenger F, Russmann S, Junker E, Wuthrich C, Bui MH, Lauterburg BH. Decreased glutathione in patients with anorexia nervosa. Risk factor for toxic liver injury? Eur J Clin Nutr. 2004;58:238-243.

72. Newman TJ, Bargman GJ. Acetaminophen hepatotoxicity and malnutrition. Am J Gastroenterol. 1979;72:647-650.

73. Waring WS, Stephen AF, Malkowska AM, Robinson OD. Acute acetaminophen overdose is associated with dose-dependent hypokalaemia: a prospective study of 331 patients. Basic Clin Pharmacol Toxicol. 2008;102:325-328.

74. Zyoud SH, Awang R, Sulaiman SA, et al. Relationship between serum acetaminophen concentration and $\mathrm{N}$-acetylcysteine-induced adverse drug reactions. Basic Clin Pharmacol Toxicol. 2010;107:718-723.

75. Wynne HA, Cope LH, Mutch E, Rawlins MD, Woodhouse KW, James OF. The effect of age upon liver volume and apparent liver blood flow in healthy man. Hepatology. 1989;9:297-301.

76. Chan-Yeung M, Ferreira P, Frohlich J, Schulzer M, Tan F. The effects of age, smoking, and alcohol on routine laboratory tests. Am J Clin Pathol. 1981;75:320-326.

77. Fabbri A, Marchesini G, Bianchi G, Bugianesi E, Zoli M, Pisi E. Kinetics of hepatic amino-nitrogen conversion in ageing man. Liver. 1994;14:288-294.

78. Sotaniemi EA, Arranto AJ, Pelkonen O, Pasanen M. Age and cytochrome P450-linked drug metabolism in humans: an analysis of 226 subjects with equal histopathologic conditions. Clin Pharmacol Ther. 1997;61:331-339.
79. Greenblatt DJ, Sellers EM, Shader RI. Drug therapy: drug disposition in old age. N Engl J Med. 1982;306:1081-1088.

80. Triggs EJ, Nation RL, Long A, Ashley JJ. Pharmacokinetics in the elderly. Eur J Clin Pharmacol. 1975;8:55-62.

81. Divoll M, Abernethy DR, Ameer B, Greenblatt DJ. Acetaminophen kinetics in the elderly. Clin Pharmacol Ther. 1982;31:151-156.

82. Miners JO, Penhall R, Robson RA, Birkett DJ. Comparison of paracetamol metabolism in young adult and elderly males. Eur J Clin Pharmacol. 1988;35:157-160.

83. Wynne HA, Cope LH, Herd B, Rawlins MD, James OF, Woodhouse KW. The association of age and frailty with paracetamol conjugation in man. Age Ageing. 1990;19:419-424.

84. Jones DP, Mody VC Jr, Carlson JL, Lynn MJ, Sternberg P Jr. Redox analysis of human plasma allows separation of pro-oxidant events of aging from decline in antioxidant defenses. Free Radic Biol Med. 2002;33:1290-1300.

85. Tsai CL, Chang WT, Weng TI, Fang CC, Chen WJ. Acute acetaminophen intoxication in Taiwan: outcomes and risk factors. J Formos Med Assoc. 2004;103:830-835.

86. Schiodt FV, Chung RT, Schilsky ML, Hay JE, Christensen E, Lee WM. Outcome of acute liver failure in the elderly. Liver Transpl. 2009;15:1481-1487.

87. Beckett GJ, Foster GR, Hussey AJ, et al. Plasma glutathione S-transferase and $\mathrm{F}$ protein are more sensitive than alanine aminotransferase as markers of paracetamol (acetaminophen)-induced liver damage. Clin Chem. 1989;35:2186-2189.

88. Benhalim S, Leggett GE, Jamie H, Waring WS. Proteinuria is unrelated to the extent of acute acetaminophen overdose: a prospective clinical study. J Med Toxicol. 2008;4:232-237.

89. Da Silva Melo DA, Saciura VC, Poloni JA, et al. Evaluation of renal enzymuria and cellular excretion as an marker of acute nephrotoxicity due to an overdose of paracetamol in Wistar rats. Clin Chim Acta. 2006;373:88-91.
Open Access Emergency Medicine

\section{Publish your work in this journal}

Open Access Emergency Medicine is an international, peer-reviewed, open access journal publishing original research, reports, editorials, reviews and commentaries on all aspects of emergency medicine. The manuscript management system is completely online and includes a very quick and fair peer-review system, which is all easy to use.

\section{Dovepress}

Visit http://www.dovepress.com/testimonials.php to read real quotes from published authors. 